\section{Revista Signos \\ 2010 / 43 \\ Número Especial Monográfico $\mathrm{N}^{\circ} 1$ 45-61}

\title{
Gêneros digitais: Apresentando livros na Internet ${ }^{*}$
}

\author{
Benedito Bezerra \\ Universidade de Pernambuco \\ Brasil
}

Resumo: Neste trabalho, investiga-se numa perspectiva sociorretórica os gêneros textuais introdutórios cuja circulação social se dá numa relação com a apresentação de livros acadêmicos em ambiente digital, considerando sua transmutação da mídia impressa para a virtual, e a consequente ressignificação no novo suporte. 0 propósito da investigação foi um mapeamento preliminar da ocorrência de gêneros tais como prefácios e sinopses, ligados a livros acadêmicos, em sites de diversas casas publicadoras, além da análise de aspectos peculiares assumidos por eles no novo contexto retórico. Foram selecionados 50 exemplares de gêneros em livros da área de linguística, posteriormente submetidos a procedimentos de análise segundo o modelo sociorretórico baseado em Swales (1990). Os resultados mostram uma elevada frequência do gênero sinopse, entre outros, e que esses gêneros sofrem consideráveis modificações quando veiculados pela Web, sendo a multimodalidade um dos traços bastante acentuados no novo suporte. Verifica-se ainda o papel do suporte na geração de propósitos comunicativos mistos, combinando interesses acadêmicos e promocionais.

Palabras-Chave: Gênero, gêneros introdutórios, multimodalidade, propósito comunicativo.

- Esta pesquisa contou com a participação da bolsista de Iniciação Científica Amanda Cavalcante de Oliveira Ledo, a quem agradeço pela coleta do corpus e ativa participação na análise.

Recibido:

20-XI-2009

Aceptado:

24-V-2010
Correspondencia: Benedito Bezerra (beneditobezerra@yahoo.com.br). Universidade de Pernambuco, Campus Garanhuns. Rua Capitão Pedro Rodrigues, 105, São José, Garanhuns/PE, Brasil. 


\section{Géneros digitales: Presentando libros en Internet}

Resumen: En este trabajo se investiga, desde una perspectiva socio-retórica, los géneros textuales introductorios encontrados en la introducción de libros académicos en los entornos digitales, teniendo en cuenta su transmutación del medio impreso para el medio de comunicación virtual, y los consiguientes cambios en su significado en el nuevo medio. El propósito de la investigación es el mapeo de la aparición de géneros como el prefacio y la sinopsis, vinculados a los libros académicos, en varios sitios web de casas editoriales, además del análisis de los aspectos peculiares que asumen en el nuevo contexto retórico. Se seleccionaron 50 ejemplares de géneros en libros en el campo de la Lingüística, y luego los sometieron a procedimientos de análisis de acuerdo con el modelo socioretórico basado en Swales (1990). Los resultados muestran una alta frecuencia del género sinopsis, entre otros, y que estos géneros están sufriendo cambios considerables cuando son mediados por la Web. La multimodalidad es una de las características muy definidas que adquieren en los nuevos medios. Se verifica también el papel de los medios digitales en la aparición de la mezcla de propósitos comunicativos, combinando los intereses académicos y promocionales.

Palabras Clave: Género, géneros introductorios, multimodalidad, propósito comunicativo.

\section{Digital genres: Introducing books on the Internet}

Abstract: This paper explores, from a socio-rhetorical perspective, the introductory text genres found in the introduction of digital academic books, considering both their transmutation from the printed to a virtual medium and the subsequent changes in the meaning they take on in this new medium. The purposes of this research was twofold: to map on the websites of several publishing houses the occurrence of genres, such as forewords and book blurbs linked to academic books, and to analyze the peculiar aspects they assume in the new rhetorical context. Fifty instances of such genres in books on linguistics were selected, and they were analyzed following Swales's (1990) sociorhetorical model. Findings show a high frequency of the book blurb, among others, and a considerable number of changes when Web-mediated. Multimodality is one of the most distinctive features they acquire in the new media. The role of the media in the occurrence of mixed communicative purposes, combining academic and promotional interests, is also prominent.

Key Words: Genre, introductory genres, multimodality, communicative purpose.

\section{INTRODUÇÃO}

Não constitui novidade a afirmação de que os estudos de gêneros textuais recebem atualmente particular atenção por parte dos pesquisadores nas ciências da linguagem. Hoje parece bastante evidente a necessidade de se levar a sério que "a comunicação verbal só é possível por algum gênero textual”, como bem ressaltou Marcuschi (2002: 22). Sendo a comunicação verbal um recurso central para a interação humana, a compreensão do fenômeno dos gêneros se torna, consequentemente, pré-requisito para a compreensão dos processos de interação. 
Nesse sentido, o estudo dos gêneros textuais em suporte digital, particularmente, adquire uma relevância especial e apresenta-se como uma tarefa urgente para a academia, tendo em vista a crescente visibilidade e presença das novas tecnologias de informação e comunicação (TIC) tanto nas atividades cotidianas como nos domínios profissional, acadêmico, escolar e outros.

0 presente trabalho investiga, à luz da análise de gêneros de linha sociorretórica (Swales, 1990, 2004; Bhatia, 2004), a constituição e uso dos gêneros textuais introdutórios mediados pela Web, em particular aqueles relacionados com a apresentação de livros acadêmicos, considerando sua transmutação da mídia impressa para a virtual, e a consequente ressignificação no novo suporte.

0 propósito desta investigação é contribuir para a construção de um mapeamento preliminar da ocorrência de gêneros introdutórios tais como prefácios e sinopses, ligados a livros acadêmicos, em sites de diversas editoras, além de indicar aspectos peculiares assumidos pelos referidos gêneros no novo contexto retórico. Deste modo, o interesse central da pesquisa é compreender como práticas discursivas tradicionalmente vinculadas ao suporte impresso adquirem uma nova configuração no ambiente digital.

Em vista disso, este artigo se organizará da seguinte maneira: num primeiro momento, discutem-se os conceitos teóricos de propósito comunicativo e suporte, bem como a possível influência deste sobre aquele. Em seguida, definem-se gêneros introdutórios e colônias de gêneros como noções fundamentais para o estudo proposto. Numa terceira seção, abordam-se os gêneros introdutórios situados em ambiente digital, considerando-se tanto os estudos já existentes sobre o tema como os numerosos desafios a enfrentar na investigação desse objeto. Após o estabelecimento dessa base teórica, apresentam-se os procedimentos metodológicos adotados na pesquisa, para concluir o estudo com análise dos dados e discussão dos resultados.

\section{Os gêneros textuais introdutórios em ambiente digital: Noções essenciais}

\subsection{Propósito comunicativo e suporte}

Um primeiro conceito importante, em nossa abordagem, é o de propósito comunicativo. Definido inicialmente como "critério privilegiado" (Swales, 1990: 58) para a análise de gêneros, o propósito comunicativo tem sido objeto de contínua discussão e reformulação, vindo a ser ultimamente compreendido não mais como um ponto de partida apriorístico, e sim como ponto de chegada, "como recompensa ou retribuição aos investigadores no momento em que chegam a completar o círculo hermenêutico" (Askehave \& Swales, 2009: 243). 
0 propósito comunicativo pode ser definido como sendo a ação retórica que o gênero pretende realizar, podendo ser, no entanto, analisado a partir de um olhar mais geral ou mais específico. Definido mais genericamente, trata-se de um propósito comum que permite agrupar certos gêneros, de acordo com os objetivos que compartilham, formando o que Bhatia (2004) denomina colônia de gêneros, conceito que detalhamos mais adiante.

Para Swales (1990), o gênero, encarado como evento comunicativo, caracteriza-se por apresentar um conjunto de propósitos comunicativos socialmente reconhecidos pelos membros da comunidade discursiva na qual esses gêneros circulam. Esses propósitos comunicativos definem as próprias características do gênero, na medida que constituem um repertório de estratégias que o gênero coloca em ação a fim de atingir os fins comunicativos a que se destina, cumprindo sua função como prática social. A relativa estabilidade do gênero, já mencionada por Bakhtin (1997), está em perfeita consonância com essas estratégias, que podem ser selecionadas pelo usuário da língua segundo suas necessidades, uma vez que os propósitos não devem ser vistos como um conjunto fechado e fixo de opções a seguir na elaboração do texto.

Para compreender o papel do suporte na configuração dos gêneros de modo geral e nos gêneros digitais especificamente, buscamos apoio teórico principalmente em Marcuschi (2003), que define suporte como sendo o 'portador do texto', entendido como "local físico ou virtual com formato específico que serve de base ou ambiente de fixação do gênero materializado como texto" (Marcuschi, 2003: 11).

De acordo com Marcuschi (2003), o gênero não é indiferente ao suporte, visto que a simples mudança de suporte muitas vezes pode provocar uma alteração radical na própria identificação do gênero. É o que ocorre, por exemplo, quando se transmuta a mensagem contida em um bilhete (no qual o suporte usualmente é um pedaço de papel) para um outdoor (um grande painel exposto em via pública). Isso porque o suporte não se limita a ancorar passivamente o gênero, mas contribui para a constituição do sentido deste na perspectiva tanto do produtor como do receptor. É em consonância com isso que Chartier (1998) defende a inseparabilidade entre textos e respectivos suportes, considerando que o leitor sempre interage com 'objetos de leitura', sejam eles tábuas de cera ou computadores, e não com textos vistos como abstrações. De modo específico, o propósito comunicativo necessariamente se coloca entre os aspectos a serem repensados em função de uma modificação no suporte de um determinado gênero.

\subsection{Gêneros introdutórios e colônias de gênero}

Os gêneros introdutórios são aqui compreendidos como aqueles que "introduzem ou apresentam outros gêneros" (Bezerra, 2006: 79). No que diz respeito ao livro acadêmico, bem como 
ao livro de modo geral, fatores como a ausência do autor, em decorrência do texto escrito, impresso ou virtual, ou mesmo a pouca familiaridade ou autoridade do autor diante de uma determinada comunidade discursiva, podem tornar extremamente necessária a associação de gêneros introdutórios a uma determinada obra que se pretende veicular e que, neste caso, equivale ao gênero que está sendo apresentado ou introduzido. Conforme Bezerra (2006: 80), gêneros introdutórios são:

"Os gêneros textuais que, no corpo físico do suporte em que se localiza uma obra acadêmica, usualmente se agregam ao gênero ou gêneros principais como uma proposta de leitura prévia, em termos de orientação, síntese ou convite à leitura da obra em si”.

Para atender à análise dos gêneros introdutórios em ambiente virtual, será necessário fazer a seguinte ressalva sobre essa definição: aqui se trata de gêneros que de fato propõem uma 'leitura prévia' da obra a que se referem, mas que foram deslocados de seu atrelamento 'físico'a essa obra, reproduzidos no todo com os recursos hipertextuais próprios do novo suporte ou adaptados em função do espaço disponível ou outros fatores. Portanto, se gêneros introdutórios tais como os prefácios, quando realizados em meio físico (impresso), só podem circular anexados à obra que apresentam, uma vez deslocados para o ambiente digital circulam de forma muito mais autônoma, ou, pelo menos, mantêm uma relação apenas virtual com a obra a que fazem referência. No ambiente digital, a presença física da obra é substituída por sua representação imagética (capa) acompanhada de informações como ISBN e preço, entre outras.

Por sua vez, denominamos colônia de gêneros o conjunto de textos que potencialmente é agregado ao gênero principal veiculado por uma obra acadêmica, com o propósito de apresentá-la ou mesmo promovê-la aos olhos do leitor. 0 conceito de colônia de gêneros foi inicialmente proposto por Bhatia $(1997,2004)$, tendo sido objeto de investigação, no que tange ao livro em suporte impresso, por Bezerra (2006).

Conforme essa investigação, a colônia de gêneros introdutórios a livros acadêmicos é constituída por artefatos como prefácios, apresentações, introduções, prólogos, sinopses e notas biográficas. Esses gêneros se agregam ao livro cumprindo diversos propósitos comunicativos: orientar o leitor, estabelecer as credenciais do autor, defender a relevância da publicação em apreço, entre outros. A construção desses gêneros constitui práticas sociais complexas, incluindo, entre outros aspectos, as relações de autoridade e prestígio que possibilitam a alguém ser convidado para prefaciar ou apresentar uma nova publicação. Afirmamos que os gêneros introdutórios constituem uma colônia de gêneros, considerando, ao lado dos propósitos específicos de cada gênero, um propósito comunicativo geral em comum, qual seja, o de introduzir/ apresentar determinada uma obra acadêmica. 
Conforme demonstrando por Bezerra (2006), os gêneros introdutórios a livros acadêmicos caracterizam-se, discursivamente, por uma forte presença do discurso promocional, pelo qual o livro vem a ser tratado na prática como produto comercial, e não essencialmente como obra acadêmica como seria de se esperar. Dessa forma, o discurso sobre o livro passa a ser regido mais pelas regras de mercado do que por critérios próprios do discurso acadêmico, que comumente se pretende neutro. Essa apropriação de um domínio discursivo pelo outro, prevista no conceito de 'colônia' (um domínio discursivo e seus gêneros 'colonizam' outro domínio discursivo), exemplifica o que Fairclough (2001) chama de comodificação.

Se, no suporte impresso, os gêneros introdutórios não possuem autonomia para circular isoladamente da obra e do(s) gênero(s) que apresentam, a situação muda completamente no ambiente virtual. Neste trabalho, procuramos compreender de que modo o uso desses gêneros se configura no ambiente digital, especialmente no que diz respeito a sua diversidade, bem como à multimodalidade e à hipertextualidade, considerando as peculiaridades do novo 'espaço de escrita' (Bolter apud Marcuschi, 2007).

\subsection{Os gêneros introdutórios em formato digital}

0 estudo dos gêneros digitais, cada vez mais frequente na academia, tem ressaltado suas características peculiares em contraposição aos gêneros em suporte convencional impresso, por exemplo. Por sua centralidade, o suporte, particularmente, apresenta-se como um dos aspectos mais relevantes quando se trata de gêneros que migram para o ambiente virtual.

A natureza do meio eletrônico interfere de modo significativo nos gêneros que comporta, seja acrescentando-lhes um caráter mais dinâmico e interativo, por seus recursos multimidiáticos, seja fazendo surgir novos gêneros, que por suas características próprias constituem um desafio para os estudiosos. Dois traços particularmente relevantes na configuração dos gêneros em apreço são a hipertextualidade e a multimodalidade. Esses traços não são necessariamente exclusivos do ambiente digital, mas encontram nele um terreno fértil para sua intensificação.

Dessa forma, no meio digital, em função das características e da natureza peculiar do suporte, os diversos gêneros de texto se apresentam permeados por um modo de constituição textual denominado hipertexto. 0 hipertexto pode ser descrito como uma estrutura em formato de rede capaz de interligar múltiplas informações, por meio de 'nós' que funcionam como portas de entrada ou como pontes sucessivas entre segmentos de informação, em geral integrando informações relacionadas entre si (a idéia inicial do hipertexto seria facilitar o acesso a informações interligadas por um mecanismo múltiplas associações). Na concepção de Marcuschi (2007:151): 
“O hipertexto é um tipo de escritura. É uma forma de organização cognitiva e referencial cujos princípios constituem um conjunto de possibilidades estruturais que caracterizam ações e decisões cognitivas baseadas em (séries de) referenciações não-contínuas e nãoprogressivas. Considerando que a linearidade lingüística sempre constituiu um princípio básico da teorização (formal e funcional) da língua, o hipertexto rompe esse padrão em alguns níveis. Nele, não se observa uma ordem de construção, mas possibilidades de construção textual plurilinearizada".

Some-se a isso outra característica do hipertexto que é a volatilidade: o hipertexto não ostenta a mesma estabilidade dos textos impressos, pois ali "todas as escolhas são passageiras quanto às conexões estabelecidas por seus leitores; esta característica sugere ser o hipertexto um fenômeno essencialmente virtual, decorrendo daí boa parte de suas demais propriedades" (Marcuschi, 2007: 152).

O caráter hipertextual acarreta uma expressiva diferença entre os modos de constituição dos gêneros impressos e dos gêneros digitais. É bem verdade que essa diferença se deve, em primeiro lugar, aos aspectos tecnológicos vinculados ao hipertexto e só secundariamente aos aspectos propriamente textuais. Assim é que, de acordo com Koch (2002: 61): “a diferença [do texto acadêmico impresso] com relação ao hipertexto eletrônico está apenas no suporte e na forma e rapidez de acessamento".

Mas outros pesquisadores irão além dessa concepção talvez excessivamente redutora. Num outro extremo, Xavier (2004: 171), por exemplo, afirma que “o hipertexto é uma forma híbrida, dinâmica e flexível de linguagem que dialoga com outras interfaces semióticas, adiciona e acondiciona à sua superfície formas outras de textualidade". Embora essa condição lhe seja legada essencialmente pelos recursos tecnológicos, parece evidente que o resultado de tais propriedades é capaz de afetar a própria constituição textual de uma maneira nova em relação ao suporte impresso.

Esta também é a visão de Askehave e Nielsen (2004: 11) quando defendem que:

“A web não deveria ser vista apenas como um importante traço contextual dos gêneros da internet, mas como parte integrante desses gêneros. Embora muitos gêneros tenham uma existência autônoma fora da rede, o meio acrescenta aos gêneros da web propriedades singulares em termos de produção, função e recepção".

Esse é um aspecto relevante para o presente trabalho, pois indica que os gêneros introdutórios em ambiente digital apresentam propriedades capazes de distingui-los de sua contraparte impressa. Sua apresentação se configura como muito mais do que um catálogo de livros online, possibilitando, além das relações acadêmica e comercial, uma modificação manifesta nos próprios gêneros. 
A multimodalidade se apresenta como outro traço importante na caracterização dos gêneros introdutórios em ambiente eletrônico. Para os propósitos deste trabalho, concebemos multimodalidade como a integração, em um mesmo evento comunicativo, de mais de um modo de semiotização (visual, sonoro, verbal). Hoje se torna comum defender que não existe comunicação monomodal, pois sempre integramos variadas semioses para alcançar nossos objetivos na comunicação (Dionísio, 2005). No entanto, o que destacamos aqui é o fato de, nos gêneros introdutórios digitais, esse traço se tornar muito mais saliente do que em sua contraparte impressa.

A multimodalidade, em frequente associação com o hipertexto, é responsável pelos estímulos a que o hiperleitor é submetido. Configuram-se assim artefatos textuais peculiares, capazes de submeter o hiperleitor ao que Marcuschi (2007) rotulou como 'stress cognitivo', uma vez que o hipertexto requer múltiplas escolhas na trajetória de leitura, acarretando exigências cognitivas incomuns no texto impresso convencional.

A multimodalidade liga-se intimamente à hibridizaçao dos gêneros textuais, no sentido de que, proporcionando variados recursos para sua construção, facilita a combinação de suas características com as de outros gêneros, ficando difícil a identificação de eventuais fronteiras, como alertava Paltridge (2009).

Por sua vez, a hibridização dos gêneros inviabilizará uma identificação de propósitos comunicativos clara e inequívoca. No meio eletrônico, não é incomum encontrar gêneros híbridos, pois tanto a multimodalidade quanto o hipertexto contribuem para isso. Além do mais, os gêneros introdutórios por sua própria natureza já mantêm uma relação de muita proximidade entre os respectivos propósitos comunicativos.

\section{Procedimentos metodológicos: Aproximando-nos do nosso objeto}

Central nos procedimentos adotados por esta pesquisa foi perceber eventuais diferenças acarretadas pela mudança de suporte (do impresso para o digital) na constituição dos gêneros introdutórios presentes em livros acadêmicos. Em parte, trata-se de uma análise comparativa, tomando como referencial o trabalho de Bezerra (2006), que empreende uma detalhada análise dos gêneros introdutórios em livros acadêmicos impressos, conforme mencionado anteriormente. A partir daí, queríamos saber que considerações podiam ser feitas a respeito desse processo de transmutação do impresso para o digital e que observações poderiam ser acrescentadas sobre os gêneros introdutórios para entendê-los na sua relação com o hipertexto. Através do exame do corpus descrito a seguir, procuramos investigar de que modo os gêneros introdutó- 
rios preservam suas características intrínsecas e que características adquirem em virtude do meio.

Para alcançar os objetivos que motivaram esta pesquisa, foram recolhidos para análise junto aos sites de diversas editoras 50 exemplares de gêneros introdutórios (Figura 1). A coleta levou em conta o critério de diversidade da amostra, embora selecionando preferencialmente livros da área de Linguística, uma vez que a não observação de fronteiras disciplinares poderia eventualmente comprometer os resultados no que diz respeito aos procedimentos de construção dos gêneros.

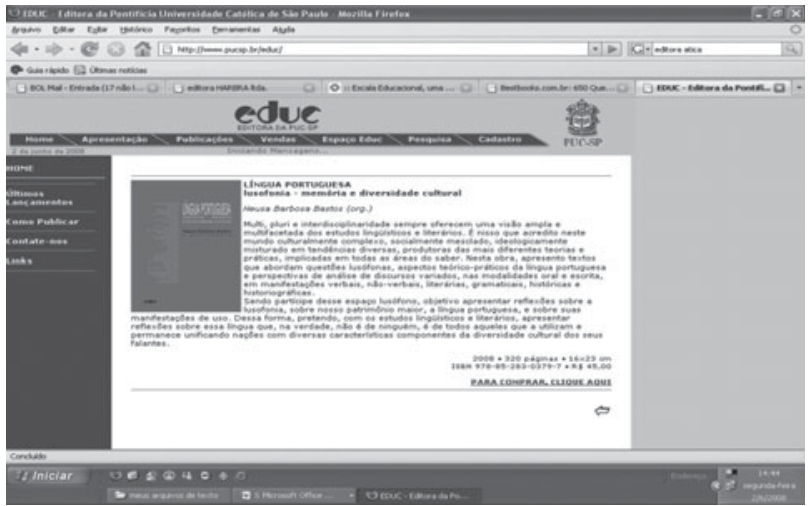

Figura 1. Apresentação de livro na internet.

Após a coleta, organizou-se o corpus, formando subgrupos com os diversos exemplares de acordo com as respectivas editoras. Posteriormente, cada exemplar de texto foi submetido a uma rigorosa leitura para descrição dos elementos presentes em cada um (Figura 2). 


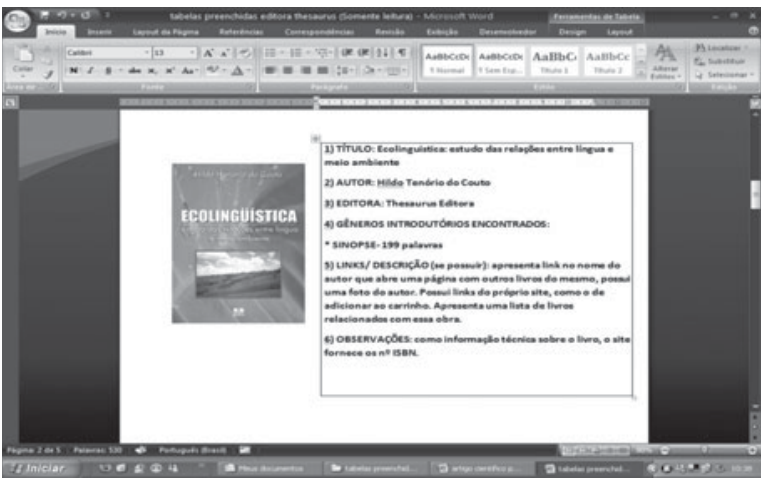

Figura 2. Descrição dos gêneros introdutórios.

A partir dos exemplares recolhidos, foi possivel travar contato com os referidos gêneros introdutórios, já definidos por Bezerra (2006) no que diz respeito ao meio impresso, agora em ambiente digital. Esse levantamento inicial possibilitou a percepção de algumas características primordiais, como, por exemplo, quais gêneros eram mais frequentes e qual o papel da estrutura hipertextual na apresentação desses gêneros.

Em seguida, procedeu-se a uma análise mais aprofundada tendo em vista os objetivos propostos para o estudo. Com base nas concepções teóricas mencionadas, especialmente a análise sociorretórica baseada em Swales (2004) e Bhatia (2004), partimos para a observação sistemática das características dos gêneros introdutórios em ambiente digital, traçando a correspondência com o respectivo gênero impresso.

\section{Gêneros introdutórios em meio digital: Algo novo debaixo do sol?}

Como se podia esperar, observamos primeiramente que cada editora adota, em seu site, um modelo próprio de apresentação da obra ao visitante do site, umas fornecendo mais, outras menos informações sobre as obras, apesar de no geral oferecerem elementos em comum, como a sinopse e as informações mais técnicas. Informações mais detalhadas sobre a obra foram 
encontradas quando o site disponibiliza um espaço razoável para a promoção da mesma. Isso implica que não haja uma grande quantidade de anúncios vinculados às páginas de apresentação dos livros. Assim, foi possível relacionar a quantidade de informações oferecidas a respeito do livro com o espaço reservado no site para outras propagandas. Observa-se que o livro, nos sites de editoras, apresenta-se mais como um produto entre outros produtos do que como uma obra avaliada por sua contribuição científica para a respectiva área disciplinar.

Em todos os exemplares analisados percebemos a ocorrência de uma imagem representativa da capa do livro. Essa característica, expressamente multimodal, evidencia que o meio digital possui propriedades que permitem aos gêneros incorporar características desse suporte, o que de alguma forma é vantajoso, visto que esses sites se voltam para a venda das obras, entre outros produtos. Nessa (possível) relação comercial, é interessante que o anunciante/vendedor aproxime o produto do consumidor o máximo que puder, e colocar uma imagem da capa do livro é uma maneira de suprir a ausência física do livro diante do leitor/consumidor.

Dentre as informações apresentadas a respeito do livro, a que mais se destacou, por se fazer presente em todos os exemplares analisados, foi a ocorrência do gênero sinopse. Esta, conforme analisou Bezerra (2006), constitui-se como um resumo ou síntese do conteúdo da obra, para que o leitor saiba do que se trata e se a obra é do seu interesse. Muitas vezes, ao lado da sinopse, encontramos um espaço reservado a comentários de pessoas que compraram o livro, como forma de conferir ao produto uma maior "confiabilidade" aos olhos dos leitores, com intuito promocional. Isso confere ao gênero um caráter interativo que é novo em relação à sua contraparte impressa. 0 gênero adquire, dessa forma, um caráter inacabado, deixando em aberto tanto a questão da autoria como os próprios limites textuais.

Alguns sites disponibilizam o acesso a partes do próprio livro, bem como a outros gêneros introdutórios, sendo o acesso sinalizado por meio de links. Através de um link como 'faça o download da apresentação da obra', por exemplo, pode-se ter acesso a um arquivo em formato pdf, que possibilita ao leitor o contato com informações mais diretas a respeito do livro e de seu conteúdo. A rigor, é como se o interessado pudesse folhear a obra, antes de se dispor a adquirila de fato. Trata-se de outra estratégia para suprir a ausência física do livro para o leitor.

Para a exibição online das sinopses, os hiperlinks desempenham um papel importante, funcionando como porta de acesso de um texto A para um texto B, em sites que, por alguma restrição de espaço, não podem comportar o texto integral das sinopses de todos os livros anunciados na mesma página. Em casos assim, a conexão se faz através de um link como 'detalhes', ou através de um clique sobre a expressão 'mais' ('links específicos', na terminologia de Askehave \& Nielsen, 2004), como mostra a Figura 3 : 


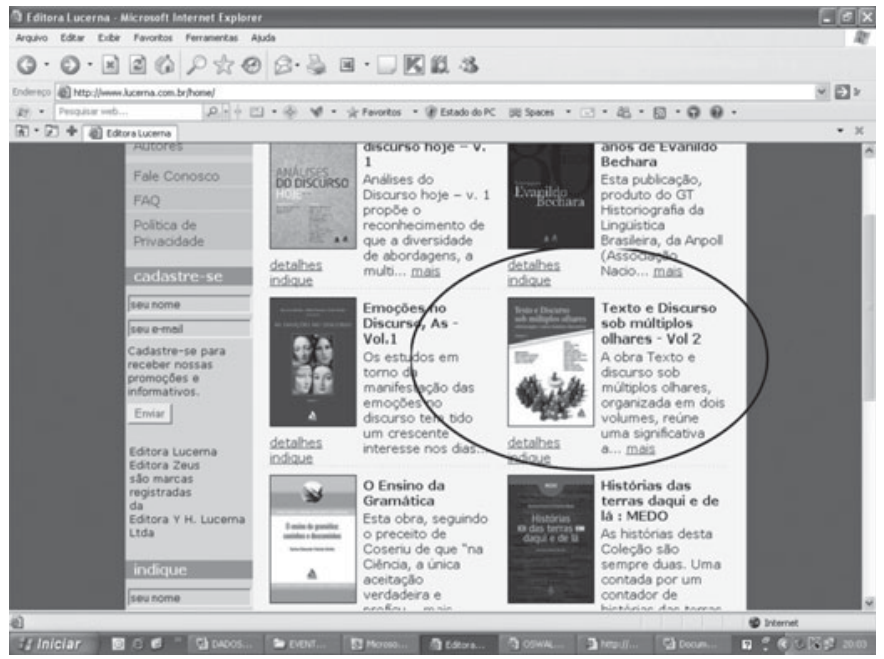

Figura 3. Links para texto completo em sinopses de livros.

Uma vez que o anunciante tenha êxito em captar o interesse do internauta, o clique sobre uma das duas expressões o conduzirá ao texto completo da sinopse (Figura 4). Observa-se que a sinopse, que tradicionalmente já se configura, no meio impresso, como uma espécie de 'aperitivo' para a leitura da obra, pode se constituir no ambiente virtual como 'aperitivo do aperitivo', sendo duplamente segmentada para atender a restrições de espaço entre os demais produtos. 0 acesso à página seguinte requer, da parte do hiperleitor, um interesse especial pela obra em questão. 


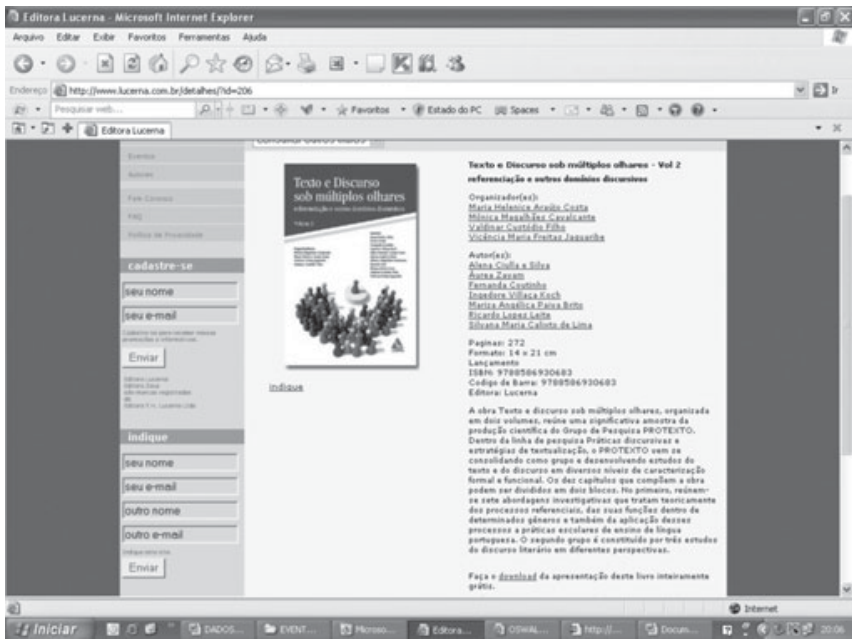

Figura 4. Texto completo atingivel pelos links.

Além disso, por meio dos links é possível relacionar a obra com outras semelhantes, seja do mesmo assunto ou do mesmo autor, por exemplo. 0 link também funciona ora como estrutura facilitadora da compra, exemplificado por 'add ao carrinho', ora como divulgador da obra, como, por exemplo, em 'indicar essa obra a um amigo'. Também observamos a presença dos links para 'comprar' o livro. No site, entre as informações disponíveis a respeito da obra em si, podemos encontrar um espaço razoável destinado a falar sobre a disponibilidade da obra, seu preço e formas de pagamento para o hiperleitor interessado em adquirir o livro. Torna-se inviável distinguir entre aspectos acadêmicos e comerciais nesse caso: os discursos se entrecruzam, confirmando e até intensificando uma característica já observada nos gêneros introdutórios impressos.

Outro aspecto a ser notado é a extensão do texto da sinopse: nos exemplares analisados, ela variou de 12 a 322 palavras. Essa diferença expressiva também pode ser relacionada ao espaço 
disponível no site: quando este disponibiliza bastante espaço para o livro, a sinopse é mais longa; quando divide o espaço com outras propagandas e informações afins, a sinopse apresenta-se resumida em poucas palavras. Além da sinopse, outros gêneros foram bastante recorrentes, como os dados técnicos, a nota biográfica, a introdução e a apresentação, embora sua forma de exibição ao leitor se dê por caminhos diferentes. A sinopse, por exemplo, é sempre mostrada na página principal de exibição do livro, em formato HTML, enquanto a apresentação é disponibilizada normalmente em arquivos pdf.

A sinopse, que conforme afirmamos é o gênero introdutório mais frequentemente encontrado, é portanto sempre exposta diretamente no próprio site, ocupando uma ou mais páginas. Quando ocupa mais de uma página, um hiperlink conduz o leitor de um fragmento do texto para o texto completo. Tal procedimento instaura, como dissemos, um aspecto novo no gênero sinopse se comparado ao suporte impresso. Nesse particular, intensifica-se uma característica de alguns gêneros introdutórios que é a fragmentariedade.

Conforme demonstra Bezerra (2006), a sinopse convencional, frequentemente transmutada ipsis litteris para o ambiente digital, muitas vezes se constitui de extratos (resumos, por assim dizer) de gêneros mais extensos, tais como a apresentação e o prefácio. No meio digital, a sinopse será reformatada numa configuração hipertextual, podendo, assim, ser segmentada como um texto 'A' que leva a um texto 'B', definidos como fragmentos de fragmentos.

Muitas vezes o site oferece a possibilidade de o leitor acessar trechos da respectiva obra, fazendo o download de partes específicas disponibilizadas através de links. Dessa forma, o leitor tem contato com o conteúdo do livro propriamente dito, ou ao menos com parte dele, pelos gêneros introdutórios já reconhecidos, como é o caso da apresentação, prefácio e sumário, ou mesmo com o primeiro capítulo. Foi possível observar a presença de nota biográfica, geralmente ao lado da sinopse ou em link ligado ao nome do autor do livro. A disposição desses gêneros no site pode apresentar caráter multimodal, como, por exemplo, pela presença de fotos da capa do livro ou do autor, entre outros.

Os links são muito recorrentes e podem exercer diversas funções, facilitando a execução de tarefas como a compra do livro e a indicação da obra para um amigo, como também mostrando ao hiperleitor livros e termos relacionados, facilitando desse modo a disseminação das informações. 


\section{CONSIDERAÇÕES FINAIS}

A partir do que foi dito, podemos fazer as seguintes considerações: a transmutação dos gêneros introdutórios do meio impresso para o virtual acarreta mudanças significativas nos gêneros, pois constatamos que o suporte interfere consideravelmente na maneira como o gênero é apresentado e recebido pelo leitor. 0 suporte assume um papel fundamental não só na circulação e materialização do gênero, mas no seu uso e interpretação, inclusive pela percepção de que a mudança de suporte pode ocasionar uma radical mudança nos propósitos comunicativos.

A utilização da Internet nas diversas atividades humanas vem revolucionando as diversas práticas discursivas, alterando gêneros já existentes e proporcionando o surgimento de outros, modificando a forma de recepção e produção deles no atual contexto. Isso exige uma reflexão a respeito dessas práticas, principalmente pelas influências que elas podem ter no tocante ao ensino e pela própria necessidade de atualização das práticas pedagógicas.

Os recursos multimidiáticos do meio eletrônico acrescentam aos gêneros que esse suporte abriga outras características, inerentes ao próprio ambiente em que se encontram, como uma intensificação da hipertextualidade e da multimodalidade. Esses aspectos passam a fazer parte da própria constituição do gênero, legando-lhes um formato mais específico, interativo, dinâmico e potencialmente híbrido. A principal diferença encontrada entre os gêneros introdutórios em meio virtual e os seus respectivos impressos é justamente a presença desses recursos.

Entretanto, igualmente notável é a presença do discurso promocional permeando esses gêneros, em detrimento de um possivel discurso acadêmico. Dentre os diversos espaços sociais de circulação do livro, bem como de sua divulgação, o site das editoras, ao contrário de espaços como bibliotecas, por exemplo, tem como finalidade prioritária a atividade comercial. 0 livro se torna, então, mais do que um instrumento do diálogo acadêmico, um produto comercial. Curioso é que a construção original dos gêneros introdutórios, embora se faça, em tese, à parte desse interesse, ligada que está ao momento de criação intelectual, ainda assim se presta na maioria das vezes a uma adaptação de seus propósitos comunicativos apenas em função da mudança de suporte e de contexto enunciativo. Em outras palavras, o que serve para promover academicamente o livro também o promove comercialmente, configurando a comodificação do discurso acadêmico criticada por Fairclough (2001).

Os gêneros digitais constituem um campo bastante produtivo e com possibilidades de ser explorado sob diversas perspectivas. Seu estudo é de grande importância tanto pelo interesse acadêmico em compreender o fenômeno como também por suas implicações para o ensino, considerando-se a necessidade de que as práticas pedagógicas acompanhem o processo de inovação tecnológica e avaliem seus impactos. 
O estudo dos gêneros cujo propósito comunicativo é apresentar obras acadêmicas ao público leitor é apenas um exemplo das possibilidades e desafios nessa área. Considerando a relação da pesquisa com as práticas cotidianas da comunidade acadêmica no tocante à eventual aquisição e leitura de livros, conclui-se que os dados do estudo, bem como seu futuro aprofundamento, podem contribuir para um tratamento mais adequado dos gêneros em questão.

\section{REFERÊNCIAS BIBLIOGRÁFICAS}

Askehave, I. \& Nielsen, A. (2004). Web-mediated genres: A challenge to traditional genre theory. Working Papers, 6, 1-50.

Askehave, I. \& Swales, J. (2009). Identificação de gêneros e propósito comunicativo: Um problema e uma possivel solução. Em B. Bezerra, B. Biasi-Rodrigues. \& M. Cavalcante (Org.), Gêneros e sequências textuais (pp. 221-247). Recife: EDUPE.

Bakhtin, M. (1997). Os gêneros do discurso. Em M. Bakhtin (Ed.), Estética da criação verbal (pp. 279-326). Ed. São Paulo: Martins Fontes.

Bezerra, B. (2006). Gêneros introdutórios em livros acadêmicos. Tese de Doutorado, Universidade Federal de Pernambuco, Recife, Brasil.

Bezerra, B. (2009). Gêneros introdutórios em ambiente digital: Uma (re)análise dos propósitos comunicativos. Linguagem em (Dis)curso, 9(3), 463-487.

Bhatia, V. (1997). Genre-mixing in academic introductions. English for Specific Purposes, 16(3), 181-195.

Bhatia, V. (2004). Worlds of written discourse: A genre-based view. London: Continuum.

Chartier, R. (1998). A aventura do livro: Do leitor ao navegador. São Paulo: UNESP.

Dionísio, A. (2005). Gêneros multimodais e multiletramento. Em A. M. Karwoski, B. Gaydeczka \& K. S. Brito (Orgs.), Gêneros textuais: Reflexões e ensino (pp. 159-177). Palmas/União da Vitória: Kaygangue.

Fairclough, N. (2001). Discurso e mudança social. Brasília: Ed. da UnB.

Koch, I. (2002). Texto e hipertexto. Em I. Koch (Ed.), Desvendando os segredos do texto (pp. 61-73). São Paulo: Cortez.

Marcuschi, L. (2002). Gêneros textuais: Definição e funcionalidade. Em A. Dionísio, A. Machado \& M. Bezerra (Orgs.), Gêneros textuais e ensino (pp. 19-36). Rio de Janeiro: Lucerna.

Marcuschi, L. (2003). A questão do suporte dos gêneros textuais. DLCV: Língua, Lingüística e Literatura, João Pessoa, 1(1), 9-40.

Marcuschi, L. (2007). Linearização, cognição e referência: 0 desafio do hipertexto. Em L. Marcuschi (Ed.), Cognição, linguagem e práticas interacionais (pp.146-170). Rio de Janeiro: Lucerna. 
Paltridge, B. (2009). Análise de gêneros e a identificação de fronteiras textuais. Em B. G. Bezerra; B. Biasi-Rodrigues \& M. M. Cavalcante (Orgs.), Gêneros e sequências textuais (pp. 61-78). Recife: EDUPE.

Swales, J. (1990). Genre analysis: English in academic and research settings. Cambridge: Cambridge University Press.

Swales, J. (2004). Research genres: Exploration and applications. Cambridge: Cambridge University Press.

Xavier, A. (2004). Leitura, texto e hipertexto. Em L. Marcuschi \&A. Xavier (Orgs.), Hipertexto e gêneros digitais: Novas formas de construção do sentido (pp. 170-180). Rio de Janeiro: Lucerna.

\section{NOTAS}

1 Um termo alternativamente usado por Bhatia (2004) é 'constelação'. Preferimos 'colônia' por ser um conceito que dá conta não só do agrupamento dos gêneros, mais ainda da influência que exercem uns sobre os outros em diversos aspectos ('colonização').

2 Para a reanálise dos propósitos comunicativos em gêneros introdutórios digitais (Bezerra, 2009).

3 Os gêneros introdutórios impressos podem apresentar formas bem menos notáveis de traços multimodais ligados geralmente ao próprio texto (tamanhos diferenciados de fontes, estilização de letras iniciais, entre outros). Uma exceção é a nota biográfica, que usualmente combina a fotografia do autor com uma parte textual. 